\title{
The Epidemic of Chronic Noninfectious Diseases: New Conception of Prophylaxis
}

\section{Apanasenko GL*}

Department of physical and rehabilitation medicine of the National medical academy of postgraduate education the name of PL Shupik, Kyiv, Ukraine. Center of health and longevity "AgeFree"

*Corresponding author: Apanasenko GL, Department of physical and rehabilitation medicine of the National medical academy of postgraduate education the name of PL Shupik, Ukraine, Tel: +380677749437, Email: apanas@ukr.net

\section{Review Article \\ Volume 3 Issue 4}

Received Date: August 03, 2019

Published Date: September 03, 2019

DOI: $10.23880 /$ nhij- 16000198

\section{Abstract}

Worked out the total to long-term researches of author. A human organism is examined as an open thermodynamics system. Her stability at influence of unfavorable factors of environment is determined by potential of her energy. The index of this energy is maximal aerobic power (maximal consumption of oxygen). It is an index in the $\mathrm{ml} / \mathrm{of} \mathrm{min} / \mathrm{mass}$ of body can be considered quantitative description of somatic health. Having a quantitative index, it is possible to manage a health. The phenomenon of «safe» health level is first described, endogenous risk and disease factors do not register oneself higher than that. Him quantitative description is given to. On leaving of individual from the «safe zone» of health the phenomenon of «selfdevolopment» of pathological the process is formed. It is necessary in addition to «industry of illness»(establishments of ministry of health) forming of «industry of health», in basis of that maintenance and increase of aerobic power potential of the biosystem at population level.

Keywords: Thermodynamics conception of health; Health level; Industry of health, Sanocentric strategy of health protection

\section{Introduction}

The greatest problem of modern health protection is chronic noninfectious diseases (CND). In the developed countries they come forward as reason more than in $80 \%$ of all cases of death. The stake of deaths is especially high from the diseases of the cardiovascular system, here is a permanent height of this index. The government and international programs (for example, CINDI) did not change a situation. Appeared, that a hope to improve the health of population due to conception of risk factors is illusive, because a fight against them does not diminish the amount of diseased. This conception answers a question "how" does not answer a question "why". All anymore appears works in that a reasonable doubt speaks out concerning ability of traditional prophylactic approaches to influence on a general death rate [1,2]. Classic endogenous risk factors in a number of situations can come forward risk indicators, predicting the origin of illness, but their correction improves a prognosis not necessarily. In addition, there is the phenomenon "of pumping over of death rate" [1], when the decline of death rate from one diseases is accompanied by the 


\section{Nursing \& Healthcare International Journal}

increase of death rate from other, not giving a result from the point of view of increase of life-span [3].

In an order to estimate evidentialness of statement, in accordance with that the multivariable prophylaxis of ishemic heart disease (IHD), sent to the correction of traditional risk factors, provides the decline of general death rate, I. Gundarov and other [1] undertook a fundamental study, that an analysis of efficiency of the known prophylactic programs is the basis of from the point of view of evidential medicine.

As material the results of the large multivariable programs making "the gold" fund of epidemiology of uninfectious diseases and medical prophylaxis are used. The conducted analysis showed that from 23 programs only in one a general death rate diminished, in three increased, in other the distinction appeared unreliable. The same a null-hypothesis about ability of traditional multivariable prophylaxis of IHD to influence on a general death rate was not confirmed.

It is necessary to underline that a death rate did not diminish even at the expressed decline of endogenous risk factors. It suggests an idea, that they really are risk indicators helping to forecast an unfavorable situation, however their minimization (removal) improves a prognosis. The participants of the prophylactic programs establish: «Researches of multivariable primary prophylaxis on the decline of cardiovascular diseases generated disappointing results ... distinctions of general and coronal death rate between the groups of interference and control appeared reduce» [4]. Drawn conclusion about prematurity of distribution of this approach on a practical health protection [5]. To the analogical conclusion researchers came at the analysis of the later multivariable prophylactic programs, published in «bible» of evidential medicine - Cochrane review [6]. Validity of fear is confirmed by the height of death rate shown in a number of the considered projects on the start of prophylaxis, that means an increase in the groups of interference of number of the lost years of life.

Absence of convincing proofs of efficiency of the programs of multivariable prophylaxis of IHD in regard to the decline of cardiovascular and general death rate puts on an order-paper the question of changing of existent paradigm of medical prophylaxis and development of the new going near forming of healthy way of life and strengthening of health of population. Development of innovative organizationally-functional model of warning of surplus death rate is required from noninfectious diseases, strategy of individual mass prophylaxis, being based on principles of measuring of backlogs of health of man, can be fixed in basis of that $[7,8]$.

\section{Theoretical bases}

Nothing in the world takes place without the expenses of energy. It touches and life as process $[9,10]$ and than more energy potential of the biosystem, the she steadier to external and internal influences [7,9]. Formation of energy in the living system is a process of transformation of sunny energy in other types of energy. An eventual link of formation of energy in the living system and her accumulator are mitochondries. Efficiency of their activity at organism level shows up in maximal possibilities of aerobic energy (maximal consumption of oxygen-MCO, $\mathrm{ml} / \mathrm{min} / \mathrm{kg}$ ). Thus, viability of the biosystem is characterized by her energypotential that can be identified with a somatic health level measured [11]. And it means that it is possible to manage (to control, save, restore, strengthen) viability by a health.

In the process of evolution there is perfection of efficiency of the intracellular breathing [12], i.e. exists for form's sake Homo Sapiens the evolutional conditioned threshold that we named a «safe» health level (SHL) and gave quantitative description to him [11,13]. Higher SHL (12 MET for men and 10 MET for women) register oneself neither endogenous risk of chronic uninfectious diseases (cardiovascular, malignant, endocrine and other) factors nor diseases.

At influence of negative factors of environment, unhealthy way of life, aging, etc. there is a decline of efficiency of intracellular form energy. In accordance with thermodynamics conception of health and prophylaxis [13] the exit of efficiency of intracellular form energy outside SHL is accompanied by the phenomenon of «selfdevolopment» of pathological process and is primary cause of epidemic of SND (a decline of energypotential is a height of entropy-chaos of functions-pathology). At distribution of similar changes in the scale of population, except development of epidemic of SND, an aging rate is accelerated, a reproductive function suffers, the physical and i psyhophysical internalss of and other go down, i.e. the phenomenon of biological degradation of Homo Sapiens is formed [14].

First reaction of organism on a defect ATP in cages is an increase of arteriotony [15]. Thus, fight against endogenous risk of development of SND factors without the increase of energypotential of the biosystem to the level conditioned by an evolution (SHL), - ineffective. Researches of Myers J [16] confirmed our the data that 


\section{Nursing \& Healthcare International Journal}

subzero indexes of aerobic capacity are more powerful predictor of cardiovascular morbidity and general death rate, what other cardiovascular risk factors, such as a hyperpiesis, smoking, lipidemia and diabetes mellitus. An Aspenes S a.o. [17] in researches of the healthy Norwegian population confirmed our the data about the presence of SHL, showing that every decline of MCO on 5 $\mathrm{mls} / \mathrm{mines} / \mathrm{kg}$ below SHL increases the risk of development of cardiovascular pathology on 56\%. To the present tense metaanalysis of publications appeared on this issue, that confirms the indicated conformities to law [18]. We will bring also the most complete and evidential research over of the American scientists from Medical Center of veterans in Washington. They from 1986 to 2008 watched 5314 veterans of war of the USA (P Kokkinos, J Mayers a.o.). Appeared, that every increase of maximal aerobic ability on 1 MET reduced the risk of death on 13\%. F. Booth a.o. [19] Generalized these data and presented them as a chart. Pays attention on itself catastrophic height of death rate, since maximal aerobic power in 10-12 MET (35-42 mls/of kg/of min) (Figure 1).

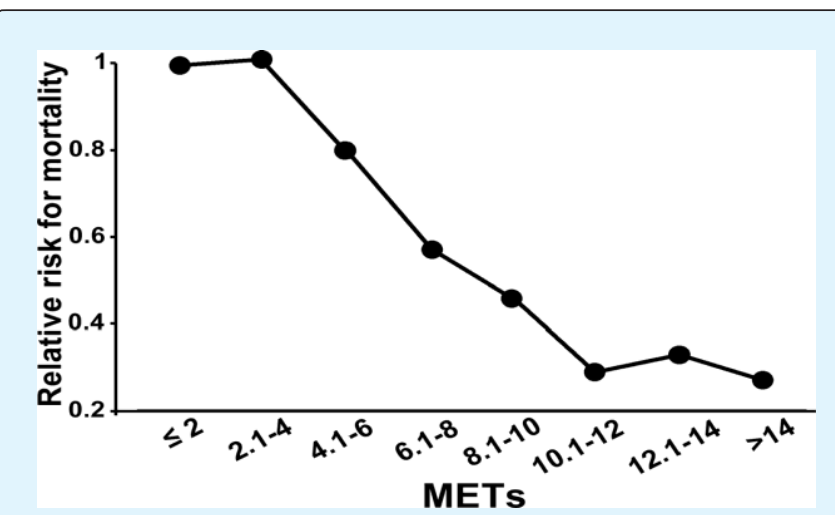

Figure 1: Risk of death for the veterans of war of the USA depending on MCO [19,20].

Thus, morbidity and death rate of modern population are conditioned, mainly, by the decline of energypotential of the biosystem (health level), and SND - only investigation of this process.

Actually, nobody of drivers will search direct reason of failures in-process car, if an accumulator is discharged. And doctors search the hidden reasons of illness until now. Although here they - lie on a surface: mitochodries, i.e. intracellular accumulators, is discharged.

In spite of all complication of organization living there are three major components of the living system (cages), providing life: accumulator of energy, delivery of high quality substrat and oxidant system for his incineration, and also system of selection of exhaust foods to the vital functions. And all this is managed by a complex regulative center being, in turn, from the nervous system, system of the endocrine adjusting and immunity. If function of these all of the tools living will be accordingly provided, the system will exist infinitely long. Sanocentric strategy of health protection consists herein.

Pathocentric strategy of health protection is realized in practice of health protection, in the spotlight of that pathological process. To expect the substantial strengthening of health of population at financing mainly of sphere of curatively-diagnostic help senselessly. (To hope on it - however, that to expect the decline of criminality at a fight against her in prisons). Pathocentric strategy is fraught the crisis of health protection, because new technologies of diagnostics and treatment with every year become all more expensive and already inaccessible to the ordinary patient.

In respect of the sanitary-hygenic providing, then it shows by itself, in fact, passive way of warning of pathology, and does not relate to strengthening of the open thermodynamics system, which an organism of man is.

\section{Ways of Decision of Problem}

Substitution of concepts a «health» and «illness» at the level of state and territorial administration result in the acceptance of wrong administrative decisions: we talk about a health - we imply illnesses.

An innovation allowing during the nearest years to provide reproduction and forming of new high quality of human capital is creation of the «industry of health» (in addition to existent «industry of illness» - establishments of Ministry of health), built on sanogenetic conception. At the investment of facilities in a health practically healthy man the necessity of financing of problems of sick people will diminish appropriately.

Presently independently without participation of the state industry of health is formed as centers of fitness, shaping, health centers of and other. But they are created without a due scientifically-technological ground, approach of the systems, professional and application of management technologies by a health.

We are give definition of category «individual health» with the use of operational criteria (id est such that can be reproduced identified) and a case frame is created by the 


\section{Nursing \& Healthcare International Journal}

health of man [2]. Health it is ephemeral not «well-being», as WHO asserts, but ability of individual to carry out the biological (survival and reproduction) and social functions.

Only at joint determination of indexes of health and illness and their comparison it is possible to talk about the prognosis of the state of health of concrete man and present for him diseases, and also determine correct strategy and tactics of making healthy and treatment. Making healthy must come true constantly, and treatment - if necessary.

In connection with the stated, management by vital functions and health of man must come true by a management by energy potential of the biosystemphysical activity (perfection of function of mitochondries), feed (i.e. by the consumption of energy, information and substance), optimization of internal environment of organism (leading out of foods of exchange); by a recreation, preparation to realization of reproductive function of and other.

Orientation on treatment of patients, but not on maintenance and strengthening of health resulted in that now there are hundreds of specialities and specializations on illnesses, and there is not a single scientificallyconfessed medical speciality, investigating the phenomenon of health. Hygienical science studies influence of factors of environment on morbidity and death rate, and essence and phenomena of health do not investigate.

Everybody must save, strengthen and responsible for an own health, health native and near. But for this purpose he must be well-informed about essence of problem.

\section{Conclusions}

Existent conception of prophylaxis of chronic noninfectious diseases as a fight against risk factors cannot be confessed by successful. On changing thermodynamics conception of prophylaxis must come her. A human organism looks like any other mechanism: for his functioning energy is needed. It is well-proven by us, that a level of intracellular formation of energy is, neither endogenous risk factors nor diseases register oneself higher than that. Him quantitative description (12 MET for men and 10 MET for women is a «safe health level») is given to. On leaving the phenomenon of «selfdevelopment» of pathological process shows up from the «safe zone» of health. It is necessity in addition to «industry of illness» (curative establishments) forming of «industry of health», in basis of that maintenance and increase of aerobic power potential of the biosystem at population level.

\section{References}

1. Gundarov IA (2016) Prophylaxis medicine on the border of centuries .From risk factors - to backlogs of health and social prophylaxis M: 341.

2. Gundarov IA a.o. (2013) Death Rate in the programs of multivariable prophylaxis ischemic heart troubles. J health protection of Russian Fed 3: 6-12.

3. Garcia Palmieri MR, Sorlie PD, Costas R Jr, Havlik RJ (1981) An apparent inverse relationship between serum cholesterol and cancer mortality in Puerto Rico. Am J Epidem 114(1): 29-40.

4. Miettinen TA, Strandberg TE (1992) Implications of recent results of long term multifactorial primary prevention of cardiovascular diseases. Ann Med 24(2): 85-89.

5. McCormick J, Skrabanek P (1988) Coronary heart disease is not preventable by population interventions. Lancet 8: 839-841.

6. Ebrahim S, Taylor F, Ward K, Beswick A, Burke M, et al. (2011) Multiple risk factor interventions for primary prevention of coronary heart disease. Cochrane Database Syst Rev 19(1): 1561.

7. Apanasenko GL (2015) The Individual health: in search of essence and quantitative estimation. Environmental health 3: 8-12.

8. Apanasenko GL (2014) Epidemic of chronic uninfectious diseases: strategy of survival. Saarbrukken: Lambert Acad Publ: 260.

9. Bauer E (1935) Theoretical biology L VIEM. pp: 157.

10. Schrodinger Erwin (1944) What is life? The physical aspect of the living cell. Cambridge Univ Press: 91.

11. Apanasenko GL, Popova LA (1998) Medical valeology. Kyiv. Health: 238.

12. Zotin AI (1981) Biopower orientation of evolutional process of organisms. Pushino: 11. 


\section{Nursing \& Healthcare International Journal}

13. Apanasenko GL (1990) Thermodynamics conception of health and prophylaxis. Ground. Archive 12: 56-58.

14. Apanasenko GL (2014) Biological degradation of Homo Sapiens: ways of counteraction. Palmarium acad Publ Saarbrucken: 102.

15. Grigorjan H (2015) Arteriotony: new idea. Kyiv, pp: 458.

16. Myers J (2003) Cardiology patient pages. Exercise and cardiovascular health. Circulation 107: 2-5.

17. Aspenes ST, Nilsen TIL, Skaug EA, Bertheussen GF, Ellingsen K, et al. (2011) Peak Oxygen Uptake and Cardiovascular Risk Factors in 4631 Healthy Women and Men. Med Sci Sports Exerc 43(8): 1465-1473.
18. Kodama S, Saito K, Tanaka S, Maki M, Yachi Y, et al. (2009) Cardiorespiratory Fitness as a Quantitative Predictor of All-Cause Mortality and Cardiovascular Events in Healthy Men and Women: A Meta - analysis. JAMA 301(19): 2024-2035.

19. Booth FW, Roberts CK, Laye MJ (2012) Lack of exercise is a major cause of chronic diseases. Compr Physiol 2: 1143-1211.

20. Oliver MF (1986) Prevention of coronary heart disease - propaganda, promises, problems and prospects. Circulation 73(1): 1-9. 